\title{
Reflections from Five Years of Research on FGM/C
}

\author{
Lori S. Ashford \\ Reshma Naik \\ Charlotte Greenbaum
}

Follow this and additional works at: https://knowledgecommons.popcouncil.org/departments_sbsr-rh

Part of the Demography, Population, and Ecology Commons, Family, Life Course, and Society Commons, Gender and Sexuality Commons, International Public Health Commons, and the Medicine and Health Commons How does access to this work benefit you? Let us know!

\section{Recommended Citation}

Ashford, Lori S., Reshma Naik, and Charlotte Greenbaum. 2020. "Reflections from Five Years of Research on FGM/C," Evidence to End FGM/C: Research to Help Girls and Women Thrive. Washington, DC:

Population Reference Bureau (PRB). 
Evidence to $(\%)$
End FGM/C

\section{REFLECTIONS FROM FIVE YEARS OF RESEARCH}




\section{Programme Overview}

From 2015 to 2019, the Evidence to End FGM/C research consortium took a fresh approach to examine the longstanding practice of female genital mutilation/cutting (FGM/C). The African-led programme developed innovative research methods and uncovered new evidence about the practice and how it is changing-focusing on families and communities, and health and legal systems.

WHAT IS FEMALE GENITAL

MUTILATION/CUTTING (FGM/C)?

FGM/C is a harmful practice that involves cutting, removing, and sometimes sewing up external female genitalia for nonmedical reasons. While considered a social norm in many cultures, FGM/C is a violation of girls' and women's rights and has no health benefits. More than 200 million girls and women have undergone $\mathrm{FGM} / \mathrm{C}$ around the world and approximately 3.6 million are cut each year. Most girls are cut before they turn 15 , and mostly by traditional practitioners, but the practice varies widely across countries and localities. In some countries, trained medical professionals are increasingly performing FGM/C, and where it is illegal, the practice is done more in secret. 


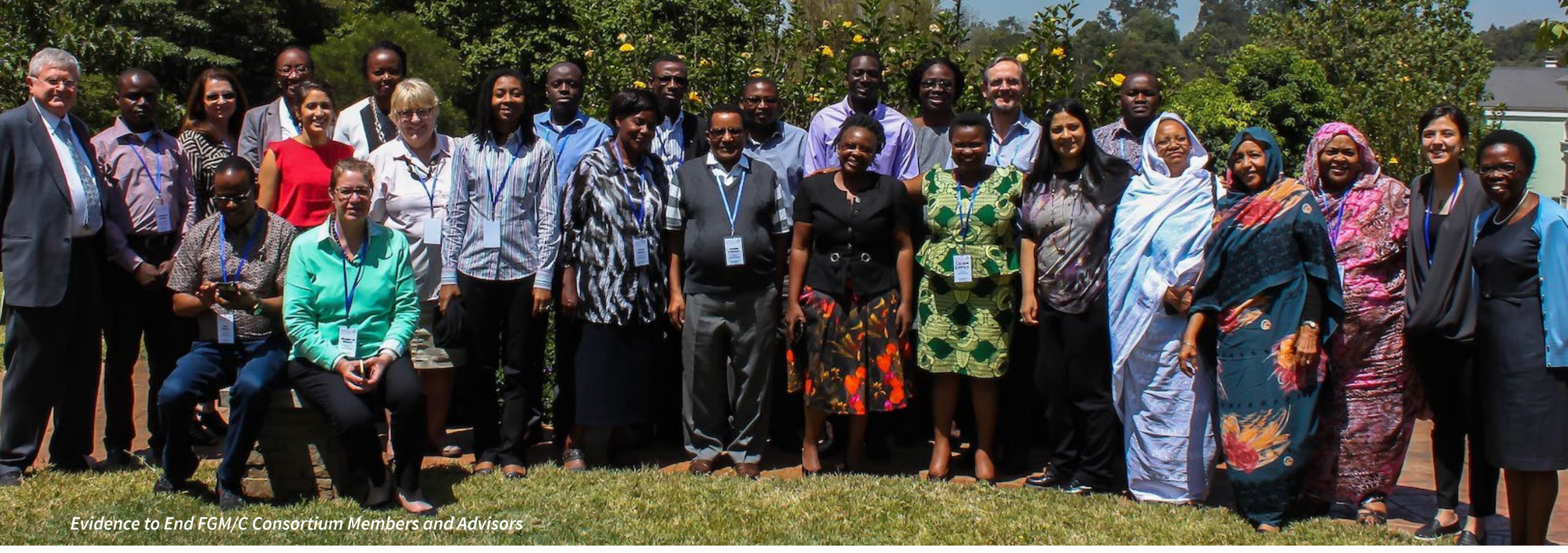

"The strength I see with this consortium is the gathering of institutions and researchers working together, bringing their comparative advantages as anthropologists, medical doctors, statisticians, and demographers. Another strength is the consortium's vision in terms of building the capacity of researchers in Africa."

NAFISSATOU DIOP, UNFPA-UNICEF JOINT PROGRAMME ON FGM/C

CHAIR, INDEPENDENT CONSORTIUM ADVISORY GROUP
Experts from multiple disciplines worked in eight African countries-Burkina Faso, Egypt, Ethiopia, Kenya, Nigeria, Senegal, Somalia, and Sudan-to dramatically expand the body of high-quality evidence on the practice in diverse societies and cultures. FGM/C prevalence varies greatly among and within these countries, yet the practice is changing in some ways in all of them.

Distinct from prior FGM/C research efforts, the consortium:

- Developed a research programme guided by a theory of change and based on local and national needs.

- Strengthened the capacity of early- to mid-career African researchers in anglophone, francophone, and Arabic-speaking regions.

- Examined FGM/C within the wider context of girls' and women's rights.
- Engaged with stakeholders before, during, and after the research to ensure the evidence would inform policies, programmes, and investments.

- Communicated evidence to diverse audiences inperson and online using the latest platforms and technologies.

The consortium conducted single and multi-country studies of the practice's many dimensions. Its aim was to bring clarity to a complex field and to converge on findings and recommendations for ending the practice in diverse communities. The programme's many resources, tools, and guides are available to researchers, programme planners and managers, and funders to support abandonment efforts.

\section{WATCH HIGHLIGHTS VIDEO}




\section{Key Lessons}

LESSON 1

Understanding local variations in FGM/C is essential for focusing investments and tailoring abandonment programmes

\section{LESSON 2}

The practice of FGM/C and its social and cultural underpinnings are changing
LESSON 3

The health sector can play a central role in preventing and responding to FGM/C

\section{LESSON 4}

Laws are necessary but require social legitimacy to be effective
"This consortium can make a huge contribution to policy and practice both at the national level and down to the local and community levels. This is the largest amount of research that's been done on FGM in Africa in such a short space of time."

HAZEL BARRETT, CENTRE FOR TRUST, PEACE, AND SOCIAL RELATIONS, COVENTRY UNIVERSITY, UK

MEMBER, INDEPENDENT CONSORTIUM ADVISORY GROUP 


\section{Understanding local variations in FGM/C is essential for focusing investments and tailoring abandonment programmes}

The prevalence of $\mathrm{FGM} / \mathrm{C}$ varies almost as much within countries as it does between them. The practice tends to be concentrated in certain subregions and locations due to clustering of practising ethnic groups; therefore, national data may mask important local variations. Subnational analyses can help programmes identify "hot spots"-highprevalence areas that would benefit from tailored interventions. Researchers can then conduct in-depth research in hot spots to examine specific community characteristics associated with FGM/C, such as ceremonies, traditions, expectations about marriage, family decision-making, and gender norms.

Using advanced statistical modelling in Kenya, Nigeria, and Senegal, the consortium's research teams were able to discern changes in $\mathrm{FGM} / \mathrm{C}$ prevalence by location, over time, and according to social and demographic characteristics. The studies lend support to those who advocate for decentralised, subnational policies to promote FGM/C abandonment.

\section{"Local variations in FGM/C can provide a true understanding of how context is shaping the many, diverse experiences of FGM/C for girls, women, and men, as well as what is driving change in the practice."}

JACINTA MUTESHI-STRACHAN, SENIOR ASSOCIATE AND PROJECT DIRECTOR, EVIDENCE TO END FGM/C HELPING GIRLS AND WOMEN THRIVE, POPULATION COUNCIL, KENYA
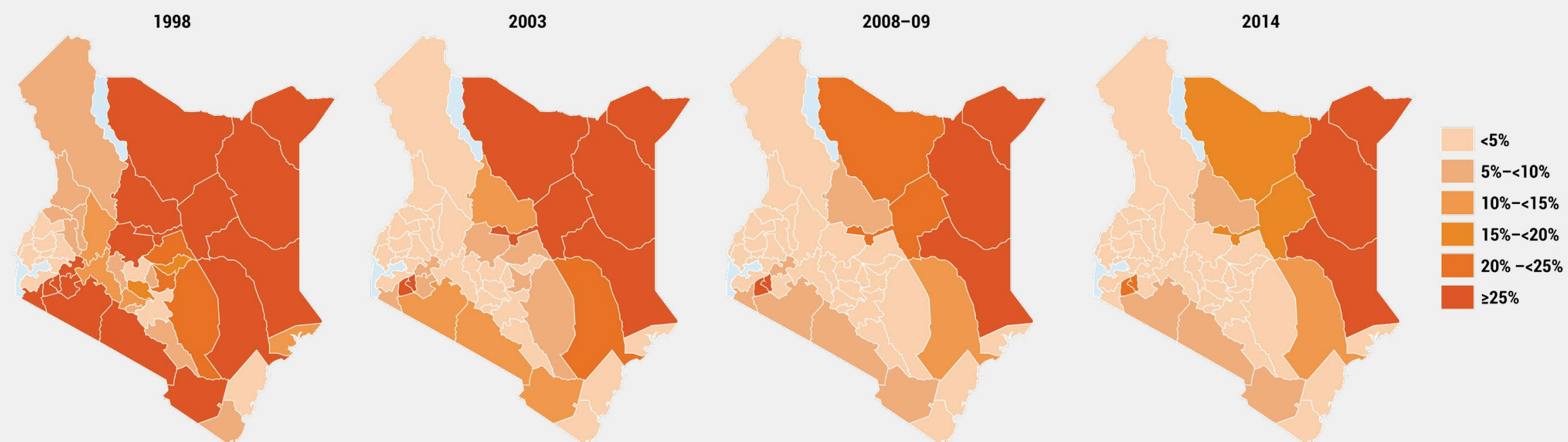

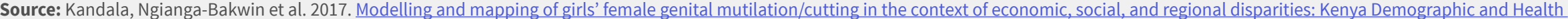
Surveys 1998-2014. 
The modelling results in Kenya showed that nationally, the share of girls younger than 15 years who had undergone FGM/C declined from 10 percent in 1998 to 3 percent in 2014. However, researchers identified five counties-hot spots-in the northeast and southwest of the country where the estimated FGM/C prevalence for girls aged 0-14 exceeded $21 \%$, the national average for older girls and women aged 15-49 years (see figure, previous page). Similar analyses in Nigeria and Senegal also showed that girls living in certain locations had a much higher likelihood of experiencing FGM/C than girls living elsewhere in the country.

The research also showed the ways in which $\mathrm{FGM} / \mathrm{C}$ is linked to characteristics such as belonging to a specific ethnic or religious group, mother's attitudes, educational level, and female autonomy. For example, a girl was more likely to be cut if her mother was cut, belonged to a certain ethnic group, and supported the continuation of FGM/C. Some of these patterns, in turn, are reinforced by community norms and expectations.

"The results of this programme are very important because previously the programming has been based on national prevalence like 'one size fits all.' With this new method, you can target your resources to this high-risk group in order to reduce female genital mutilation."

KANDALA NGIANGA-BAKWIN, PROFESSOR, NORTHUMBRIA UNIVERSITY, UK

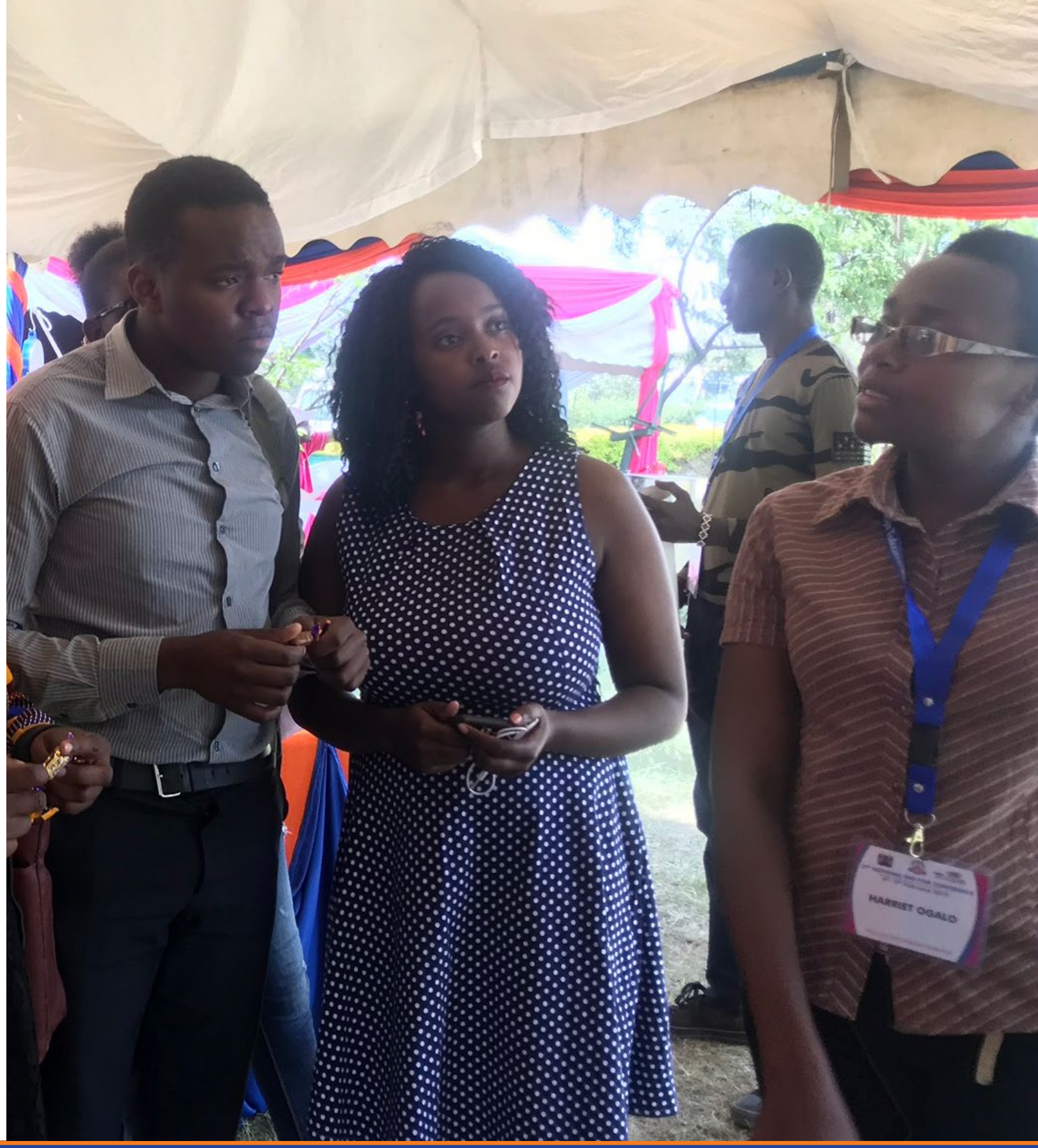




\section{The practice of FGM/C and its social and cultural underpinnings are changing}

The practice of $\mathrm{FGM} / \mathrm{C}$ is rooted in gender roles, ethnic identity, the power of community influence, and the desire to belong. It is not a religious practice, but a cultural one that reflects shared values concerning family honour, female virtue, sexual restraint, and other codes of conduct. It is passed down from older to younger generations as an obligation for community acceptance. Society members protect these values, often by ostracising those who do not conform. Undergoing FGM/C allows younger women to be included in older women's social networks.

The practice is continually evolving, however. In 15 countries, the prevalence of FGM/C among girls and women aged $15-19$ years is markedly lower than among those aged 45-49 years (see figure), providing evidence of a decline in the practice in the younger generation. In about half of these countries, such as Egypt and Ethiopia, the decline appears to be recent (not shown).

The consortium uncovered evidence about how the practice is changing and why. Some changes are similar across multiple countries (see figure, next page), and some are specific to certain regions. In Somaliland (northwestern Somalia) and in the Somali region of Ethiopia, researchers found a shift away from the most severe form of $\mathrm{FGM} / \mathrm{C}$, called
SELECT COUNTRIES WHERE FGM/C PREVALENCE IS LOWER AMONG YOUNGER AGE GROUPS, COMPARED TO OLDER

PERCENTAGE OF GIRLS OR WOMEN HAVING UNDERGONE FGM/C, BY AGE GROUP

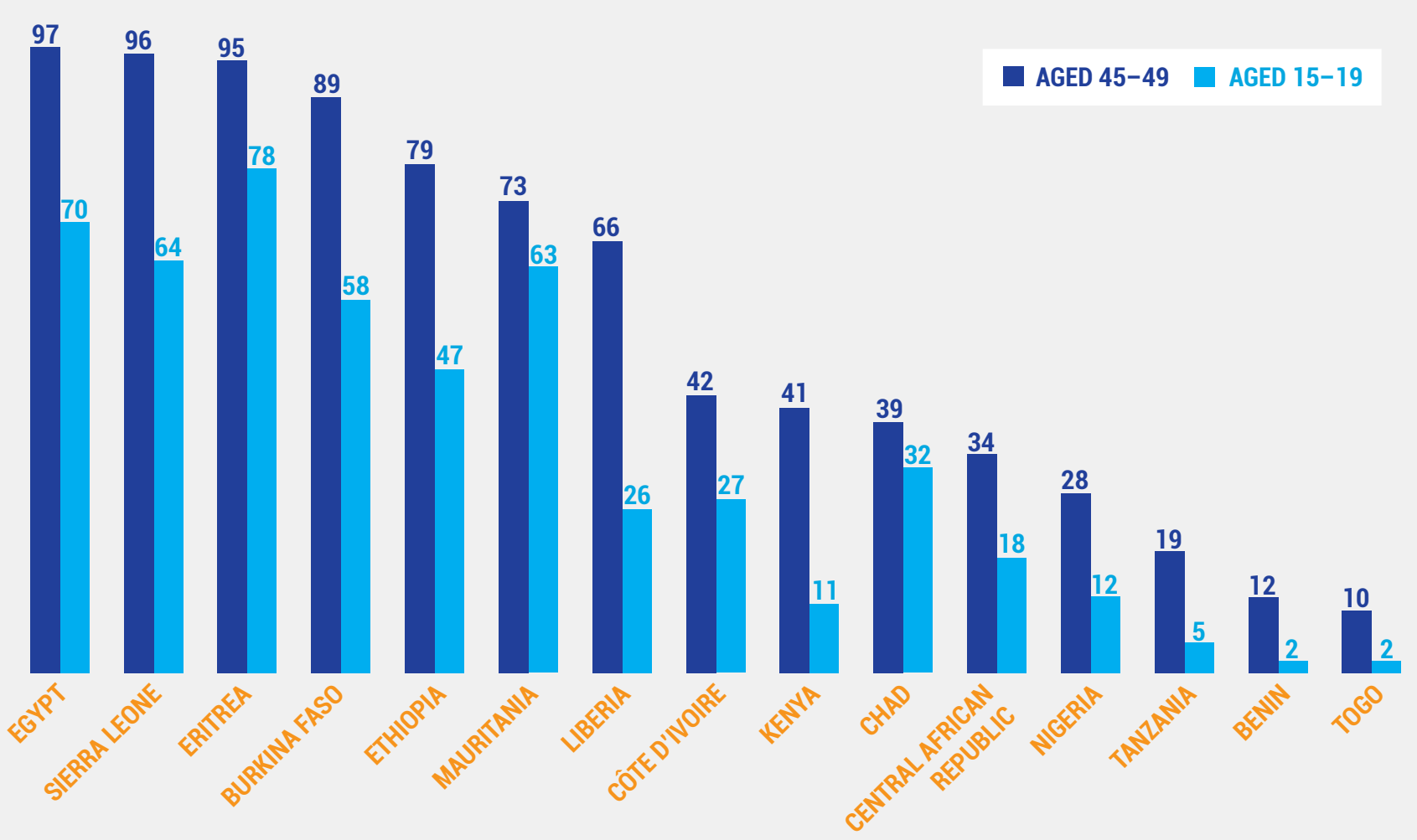

Notes: Countries with declines in FGM/C prevalence of 7 percentage points or more are shown here. Countries with no decline or a decline of less than 7 percentage points include: Cameroon, Djibouti, The Gambia, Ghana, Guinea, Guinea Bissau, Iraq, Mali, Niger, Senegal, Somalia, Sudan, Uganda, and Yemen.

The prevalence rates for Liberia are adjusted to reflect the percent of girls or women (from the whole sample) who report being members of the Sande society (a secret society that performs FGM/C during initiation).

Sources: Demographic and Health Surveys and Multiple Indicator Cluster Surveys as of 2019. 


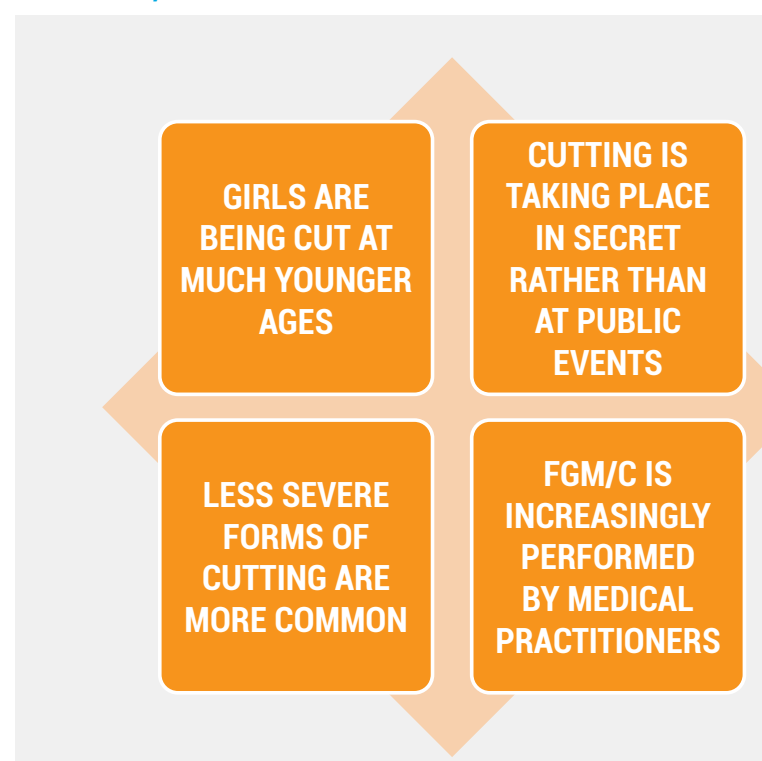

Sources: Getaneh, Mehari et al. 2020 (Ethiopia); Kimani, Samuel and Caroline W. Kabiru. 2018 (Kenya); Matanda, Dennis et al. 2018 (Kenya); Moreau, Amadou and Bettina Shell-Duncan. 2020 (Senegal); and Powell, Richard A. and Mohamed Yussuf. 2018 (Somaliland). See References.

the pharaonic cut, to the less severe "Sunna" cut, particularly in urban areas, and a shift towards cutting girls at younger ages (currently between 5 and 8 years old). FGM/C is increasingly performed by nurses and trained midwives in clinics or in families' homes.

In these countries and elsewhere, some changes in the practice, such as cutting at younger ages and by health care professionals, have occurred in response to laws banning the practice and awareness-raising campaigns focused on the health risks of FGM/C. Families are learning to manage health risks and avoid legal repercussions while preserving cultural values. Debates are common within communities about whether these changes are acceptable or whether the practice should end altogether. One study in Egypt underscored the importance of learning from the motivations and challenges of families who abandon the practice.

Other trends, such as migration, increased media exposure, and changing decision-making dynamics, are altering the social underpinnings of FGM/C. Across countries, FGM/C is less common in urban than rural settings, likely reflecting greater cultural diversity in urban settings and more widespread social norms that support abandonment.

Gender norms and expectations are also shifting. FGM/C is widely believed to increase a girl's chances of marrying; however, studies in Kenya and Senegal found some ambivalence regarding FGM/C being a prerequisite for marriage: Some study participants said it is increasingly acceptable for men to marry an uncut woman.

Mothers often make the decision to cut their daughters. Nevertheless, mothers do not decide in isolation; they are concerned about the perceptions of other members of their family and social group. Fathers are often not involved directly, and in some places, they may be more opposed to the practice than are their wives. Young men may hold contradictory positions-for example, in Senegal, some young men said they would marry an uncut girl but would prefer their own sisters to be cut.

Social norms are diverse and complex and do not lend themselves to simple interventions. However, shifts in social and cultural norms present an opportunity for advocates to contribute to dialogue at the community level and generate increased support for abandonment.

"Many informants in south and central Senegal were actively weighing the advantages and disadvantages of FGM/C in light of shifting social circumstances, making it difficult to answer the seemingly simple question: Do you support or oppose the continuation of FGM/C?"

AMADOU MOREAU, FOUNDER AND VICE PRESIDENT FOR GLOBAL INITIATIVES, GLOBAL RESEARCH AND ADVOCACY GROUP, SENEGAL 



\section{The health sector can play a central role in preventing and responding}

\section{to FGM/C}

Health care workers must be part of the response to FGM/C because they are widely respected in their communities, are ethically bound to do no harm, and are in a key position to educate patients and manage complications of FGM/C. Although the health sector seems a natural ally in the response to $\mathrm{FGM} / \mathrm{C}$, little analysis had been done of its role in the practice. The consortium examined how the health system and health care providers have either perpetuated or prevented the practice in diverse countries and communities.

\section{MEDICALISATION OF FGM/C}

Across countries where $\mathrm{FGM} / \mathrm{C}$ is practised, traditional cutters are the main providers, but medicalisation-cutting by a doctor, nurse, or trained midwife-is increasingly common in some places. Medicalisation is most common in Egypt and Sudan, where more than three-quarters of girls who have undergone FGM/C have been cut by a health care provider. Medicalisation has also increased recently in Guinea, Kenya, Nigeria, and Somalia, in part due to families' beliefs that the procedure will be safer and lead to fewer health complications.

Research teams conducted qualitative studies in Egypt, Kenya, Nigeria, and Sudan to shed light on why families opt to have their daughters cut by health professionals and why health care providers undertake the procedure (see web feature and box).

\section{UNDERSTANDING THE IMPACT OF MEDICALISATION ON FEMALE GENITAL MUTILATION/CUTTING}

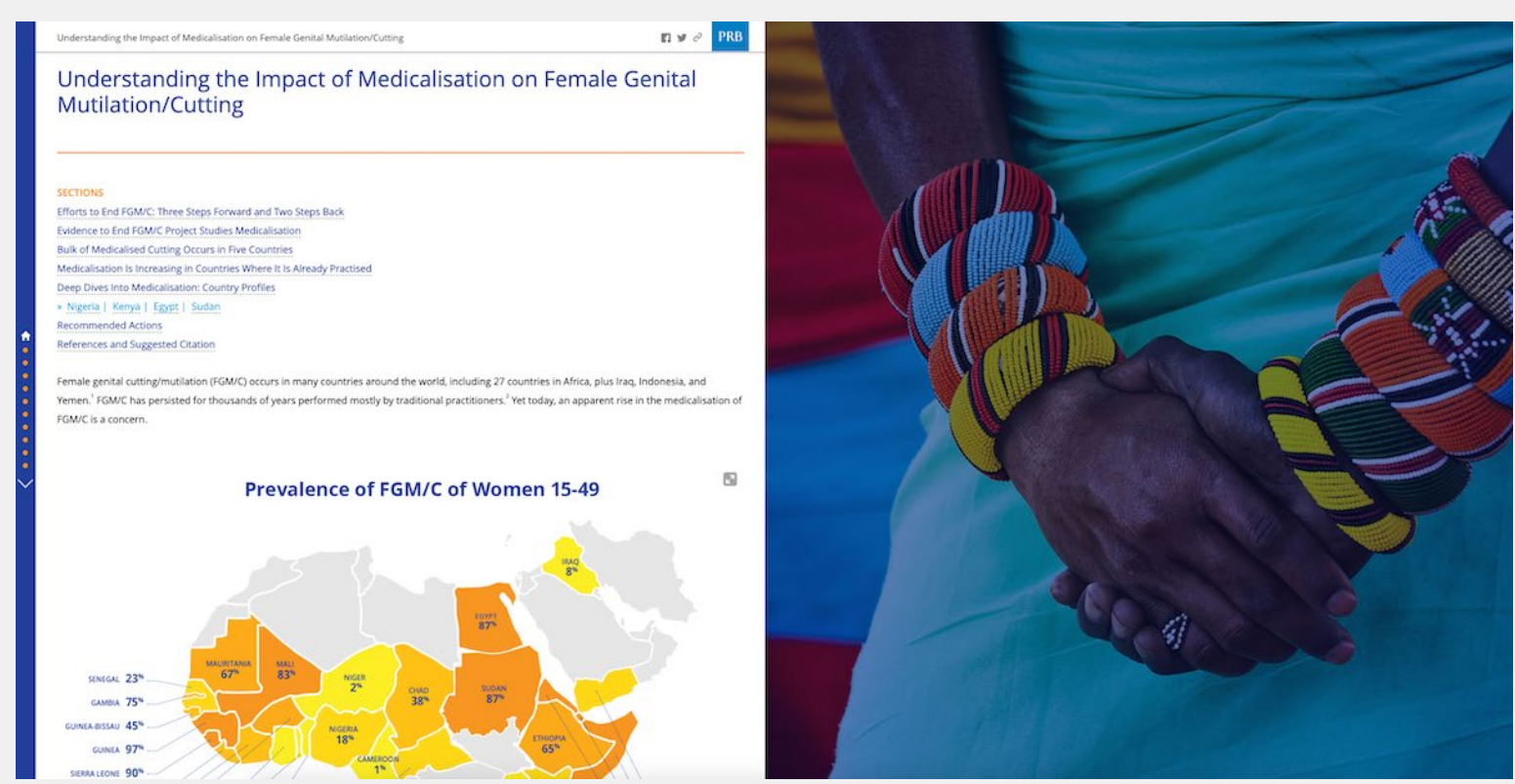

This web feature provides up-to-date information on the medicalisation of $F G M / C$, describing differences among countries and communities where it is practised and providing recommendations for abandonment. 
In Egypt, health professionals increasingly perform FGM/C even though the practice has been illegal for more than a decade. In 2014, 74 percent of girls and women aged 19 and younger who had been cut had the procedure done by a physician or nurse, making Egypt the country with the highest rate of medicalisation of FGM/C. To explore the motivations underlying medicalised cutting, the researchers conducted a qualitative study in Cairo and in Upper and Lower Egypt with health care providers and mothers. The findings suggest that parents who seek medicalised cutting are trying to minimise health risks while conforming to social expectations. Also, the social convention that ties girls' well-being to their physical beauty makes FGM/C a perceived necessity and stigmatises uncut girls. Further, some health care providers are describing FGM/C as cosmetic surgery, possibly to evade the law against FGM/C and to market the procedure to clients. The study findings suggest that social norms continue to override legal prohibitions and the medical ethic to "do no harm" to patients. The research also highlights the critical role that health care providers can play in efforts to end FGM/C in Egypt, in addition to interventions that aim to change community culture.

Source: El-Gibaly, Omaima, Mirette Aziz, and Salma Abou Hussein. 2019. Health care providers' and mothers' perceptions about the medicalization of female genital mutilation or cutting in Egypt: A cross-sectional qualitative study, BMC International Health and Human Rights 19 (26).

\section{UNDERSTANDING THE ROLE OF THE HEALTH SYSTEM}

Assessments in Kenya and Nigeria showed how the health system has responded to prevent FGM/C and where it has fallen short in terms of policy, resources, capacity, and documentation. Researchers found that:

- Although laws exist for preventing and responding to $F G M / C$, they have not been translated into specific guidelines or interventions for health care providers.

- Health workers have limited understanding of existing policies and guidelines regarding FGM/C and few resources to implement prevention activities.

- Health services do not routinely keep records of FGM/C cases and related complications.

\section{- Linkages between the health system and law enforcement are weak.}

The assessments revealed that few providers have been trained on how to talk to families about FGM/C or manage complications effectively. Health care providers do offer treatment for $\mathrm{FGM} / \mathrm{C}$ complications, but they rarely explain the negative consequences of the practice nor discuss the need to stop practising. And when women and girls do seek services for obstetric, gynaecologic, sexual, or psychological complications, the providers' limited capacity and resources undermine the quality of care provided. Sexual and psychological complications of FGM/C suffer the most neglect and are rarely remedied.
"A lot of research has focused on communities, but very little research has actually looked at how the health system is prepared in responding to management of complications and prevention of FGM. We think that this is game-changer research: Addressing people who are at the centre of it."

SAMUEL KIMANI, SENIOR LECTURER, SCHOOL OF NURSING AND AFRICA COORDINATING CENTRE FOR THE ABANDONMENT OF FGM/C, UNIVERSITY OF NAIROBI, KENYA

Research in Somaliland found similar challenges in the management of $\mathrm{FGM} / \mathrm{C}$ complications. Most women with these complications live in rural areas where there are low-level facilities with untrained providers, insufficient equipment and medicines, and few referral hospitals for $F G M / C$ cases.

These findings underscore the need for the health system to translate existing laws and policies into interventions for preventing FGM/C and offering quality care to women with complications. The consortium and its partners have emphasised the importance of ensuring that health professionals are sufficiently trained about $\mathrm{FGM} / \mathrm{C}$, provided with relevant job aids and tools, and engaged in advocacy to end the practice. 


\section{Laws are necessary but require social legitimacy to be effective}

Laws banning FGM/C have existed for decades, but the public may be unaware of them or choose to ignore them, and they may not be enforced. Law enforcement personnel may have limited knowledge about these laws or a conflict of interest, whereby they continue to support the practice to uphold community traditions or for financial gain. Understanding the motivations that prompt people to obey or defy the laws could inform legislative, policy, and programmatic changes.

Legal prohibitions of $\mathrm{FGM} / \mathrm{C}$ may promote abandonment of the practice or may drive it underground. A study in Sudan found that legal restrictions may influence families' decisions: Respondents who lived in Gedaref State, which has a law banning FGM/C, were about twice as likely to report not having their daughters cut as those who lived in Khartoum State, which has no law. Yet, the law itself can affect reporting, and evidence in other countries shows that the cutting merely continues in secret.
Research from Kenya found that variations among national laws against $\mathrm{FGM} / \mathrm{C}$ and their enforcement may prompt some families to move women and girls to a neighbouring country to practise FGM/C and avoid prosecution. Cross-border FGM/C continues across much of East and West Africa, for example, between Kenya and Somalia and between Burkina Faso and Mali.

\section{The consortium's research in} Kenya and the cross-border region between Burkina Faso and Mali investigated how criminalisation affects families' decisions to practice FGM/C. Burkina Faso and Kenya have a law banning the practice and are implementing it, while Mali does not have such a law. Researchers explored questions such as:

- Are people motivated to obey the law for moral reasons, for social reasons, or for punitive reasons?

- Does the form of the law and its enforcement, and the perceived fairness of local police and the courts, affect whether people obey the law?

\section{LEGAL STATUS OF FGM/C IN AFRICAN COUNTRIES WHERE IT IS PRACTISED}

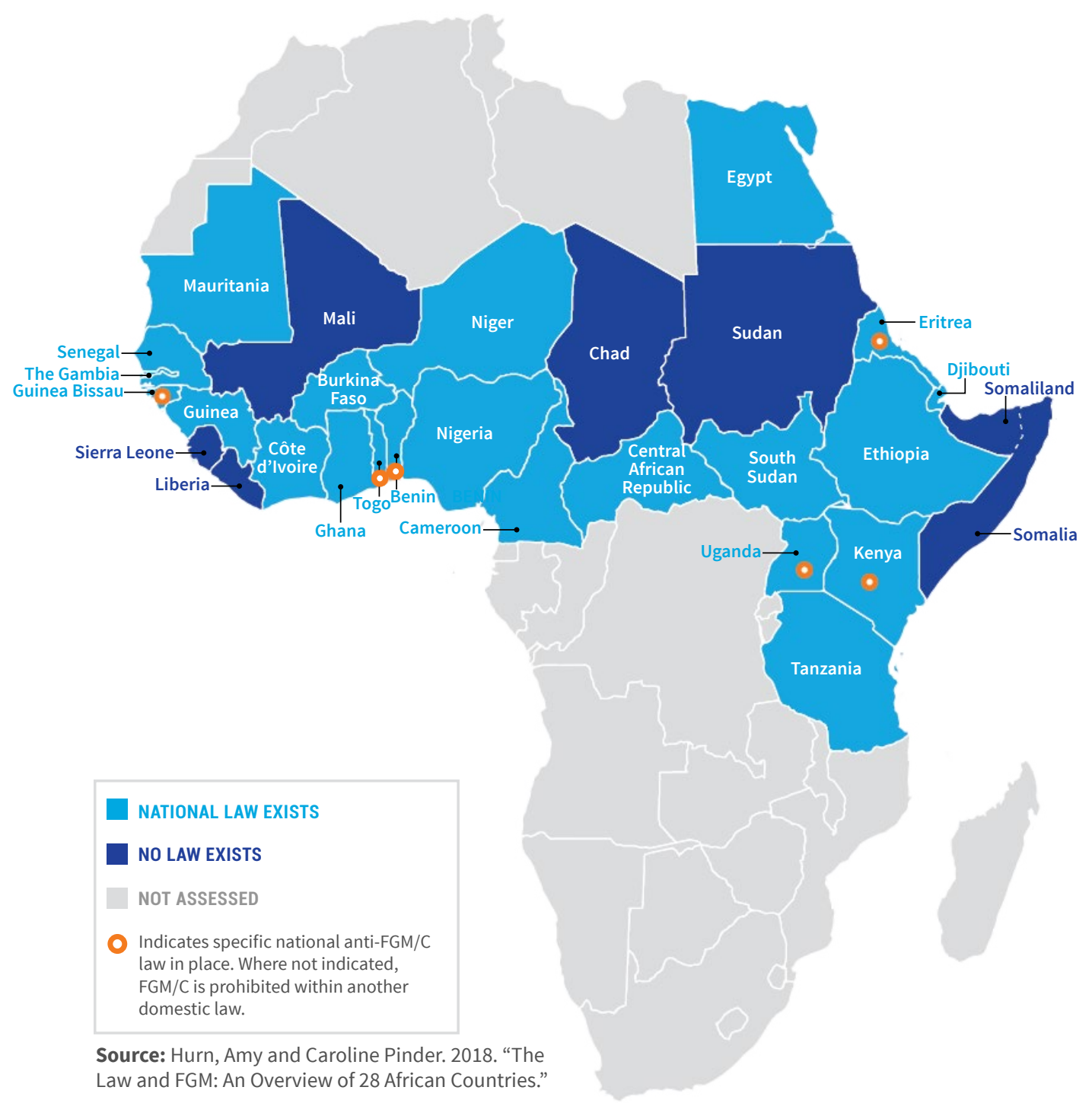


"Most research in this area is focused on how the law is implemented and puts the focus on making the law stronger. In our study, we are trying to talk to people and understand why they obey the law or why they defy the law."

JOSÉPHINE WOUANGO, INDEPENDENT CONSULTANT, BURKINA FASO AND LECTURER, UNIVERSITY OF LIĖGE, BELGIUM
The study used the unmatched count technique, a method for surveying people on sensitive or potentially incriminating topics, to increase the accuracy of responses. Results showed that 44 percent, 14 percent, and 13 percent of respondents from Mali, Burkina Faso, and Kenya, respectively, planned to cut their daughters or granddaughters. As shown in the figure, respondents from Kenya felt that in several situations, it would be permissible to disobey the law, such as when the law conflicted with religious and customary practices.
The findings highlight the need to find meaningful ways to address inherent conflicts between formal laws prohibiting $\mathrm{FGM} / \mathrm{C}$ and religion and customs, which are also recognised as sources of law. While formal laws are necessary for ending the practice, to be effective they require greater social legitimacy in the eyes of the public.

SITUATIONS IN WHICH DISOBEYING LAWS WOULD BE PERMISSIBLE, ACCORDING TO KENYAN RESPONDENTS

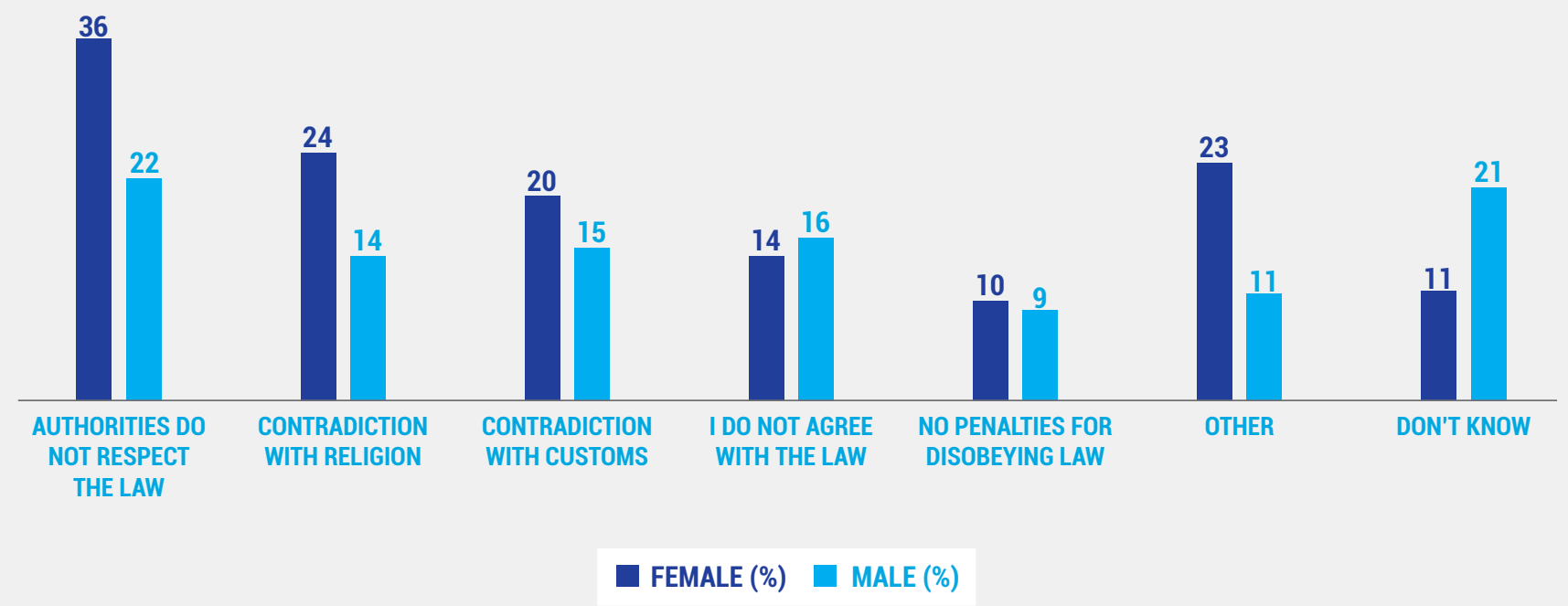

Source: Meroka-Mutua, Agnes et al. 2020. Assessing when and how law is effective in reducing the practice of FGM/C in Kenya (forthcoming.). 


\section{Improvements in Methods for Studying FGM/C}

Researching a social phenomenon as complex as $\mathrm{FGM} / \mathrm{C}$ requires digging deeper than national prevalence data and making simple correlations from large-scale survey results.

To gain a more nuanced understanding of who practises FGM/C, where, and why, the consortium used and adapted a mix of quantitative and qualitative methods from other areas of social science research. By improving the measurement of FGM/C prevalence and the analysis of social norms, the research programme has expanded the evidence base for understanding and ending the practice.

Researchers used innovative research methods to explore such questions as:

- To what extent has the practice declined in various communities?

- What factors explain why some communities have abandoned the practice and others have not?

- Who participates in the decision-making process to have daughters' cut and who holds the most influence if family members disagree?

- Which behavioural theories best explain why the practice continues?
SOCIAL NETWORK INFLUENCING FEMALE GENITAL MUTILATION/CUTTING IN SENEGAL

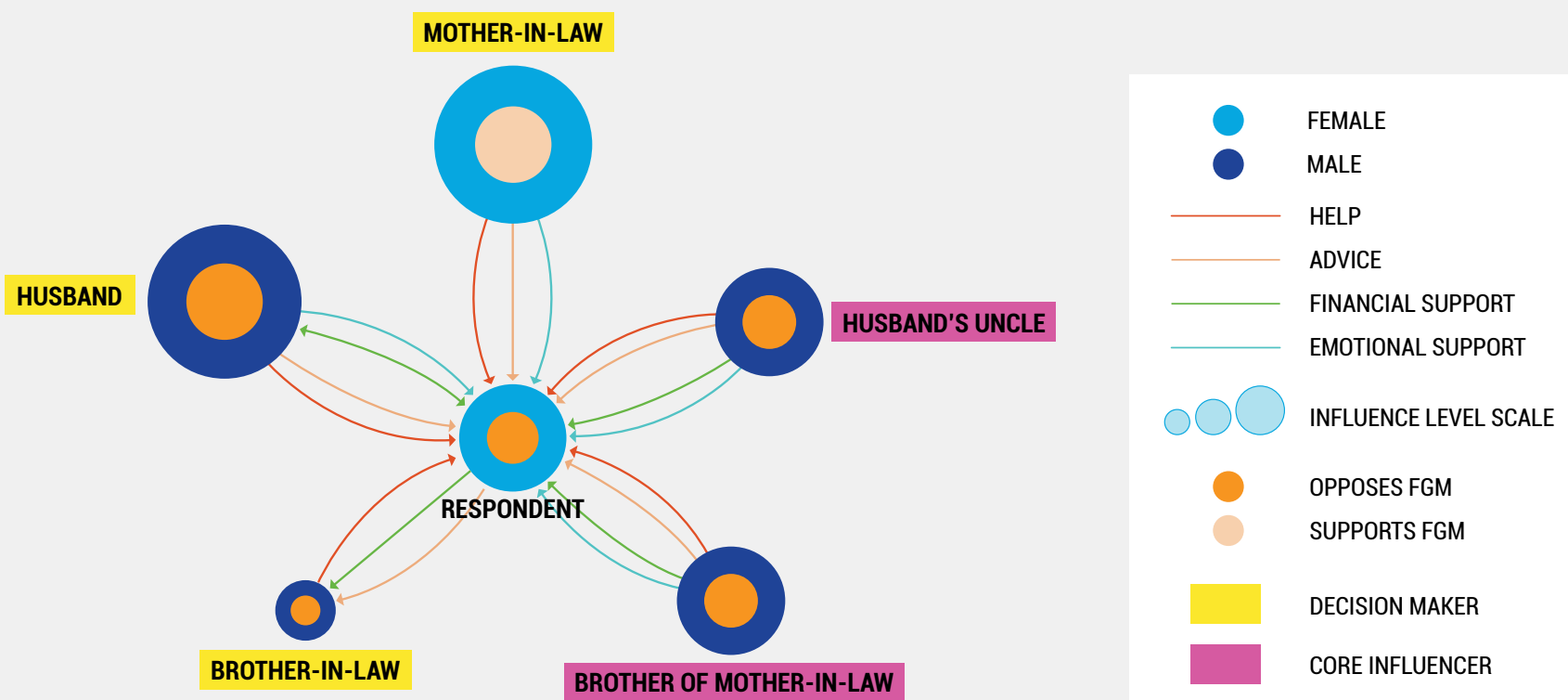

Source: Adapted from Shell-Duncan, Bettina et al. 2019. Reference guide for data collection: Qualitative social network interviews.

The study of social networks has emerged as a powerful approach for examining how interpersonal connections influence a person's attitudes and behaviours. This diagram illustrates who influences the female respondent (in the centre), the degree and types of influence they have, and whether they support FGM/C. 
The research methods used included geo-spatial analysis and geo-additive models, multilevel analysis, social network analysis (see figure, previous page), vignette-based focus group discussions, and factorial focus group analysis (see figure).

Geo-spatial analysis, for example, enables researchers to look beyond the individual characteristics linked to FGM/C, such as education and ethnicity, and consider the location of practising communities, to see whether and where the practice is declining. Social network analysis examines the social interactions between members of a community to understand the decisionmaking process that leads to girls being cut.

Vignette-based focus group discussions are one of several methods to address the problem of people underreporting a practice that they know is illegal. Researchers use hypothetical scenarios or short stories to probe FGM/C-related questions that do not force participants to give personal information about themselves but talk more generally about a situation.
The findings enable researchers to verify whether data derived from surveys, which ask people directly about practising FGM/C, are likely to be accurate.

Consortium members have published peer-reviewed research articles, book chapters, and two reference guides, on social network analysis and factorial focus group analysis, to help researchers better measure and interpret data on FGM/C.

FOCUS GROUP DISCUSSIONS IN SENEGAL REVEAL FACTORS THAT DISCOURAGE OR ENCOURAGE CONTINUATION OF FGM/C

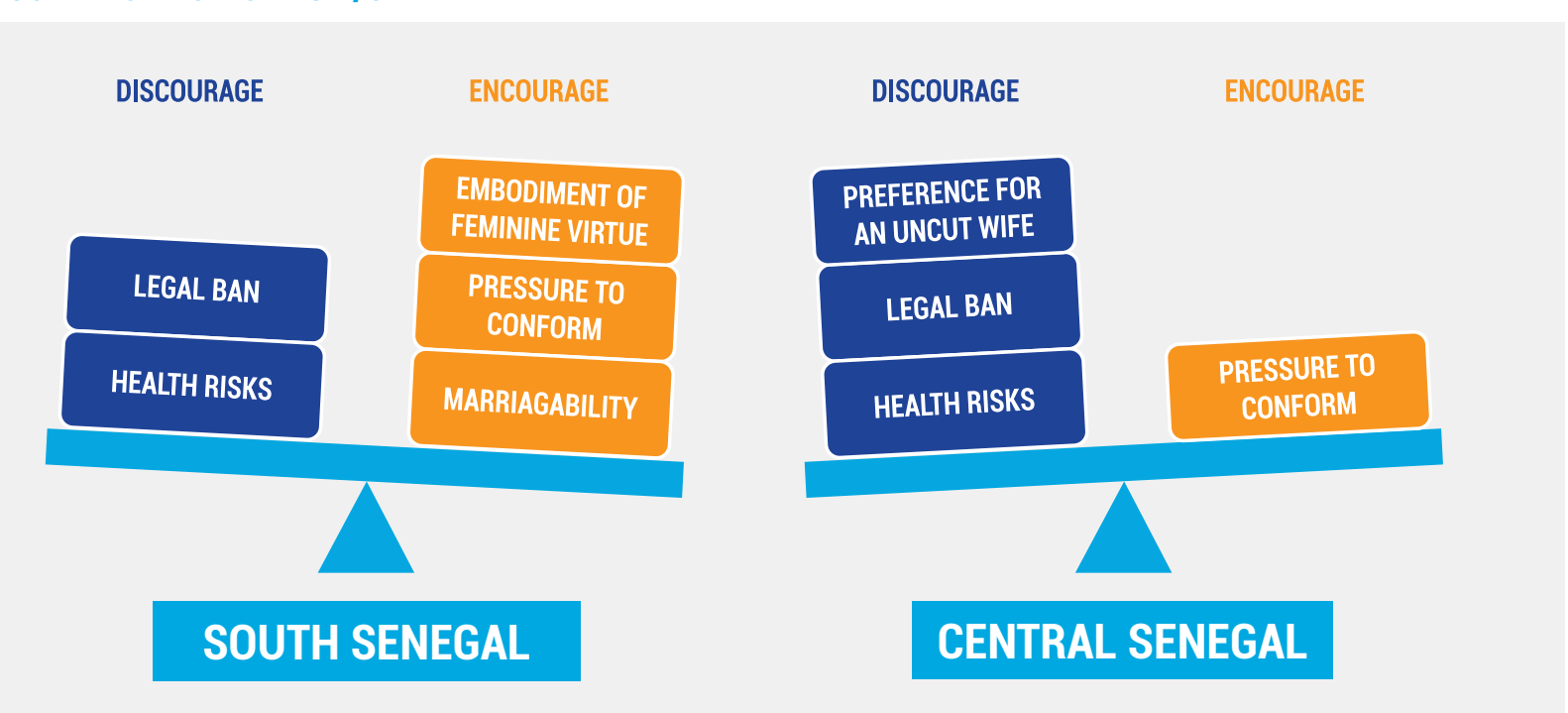
"We have used many innovative research
methods. The project itself is innovative
because talking about female genital cutting
and sexual health is taboo in our countries."

\section{ABDELHAMID ATTIA, DOCTORS AGAINST FEMALE GENITAL MUTILATION \\ MEMBER, INDEPENDENT CONSORTIUM ADVISORY GROUP}

Source: Moreau, Amadou. 2019. "The role of gender in Senegal.” Paper presented at the Joint Partner Independent Consortium Advisory Group meeting, Nairobi, Kenya, March 6, 2019.

This figure displays the results of focus group discussions that followed the factorial focus group methodology. The boxes on the scales represent the social norms or factors that drew consensus among the discussants; some factors discourage the continuation of FGM/C while others encourage it. 


\section{Strengthening the Capacity of Researchers in Africa}

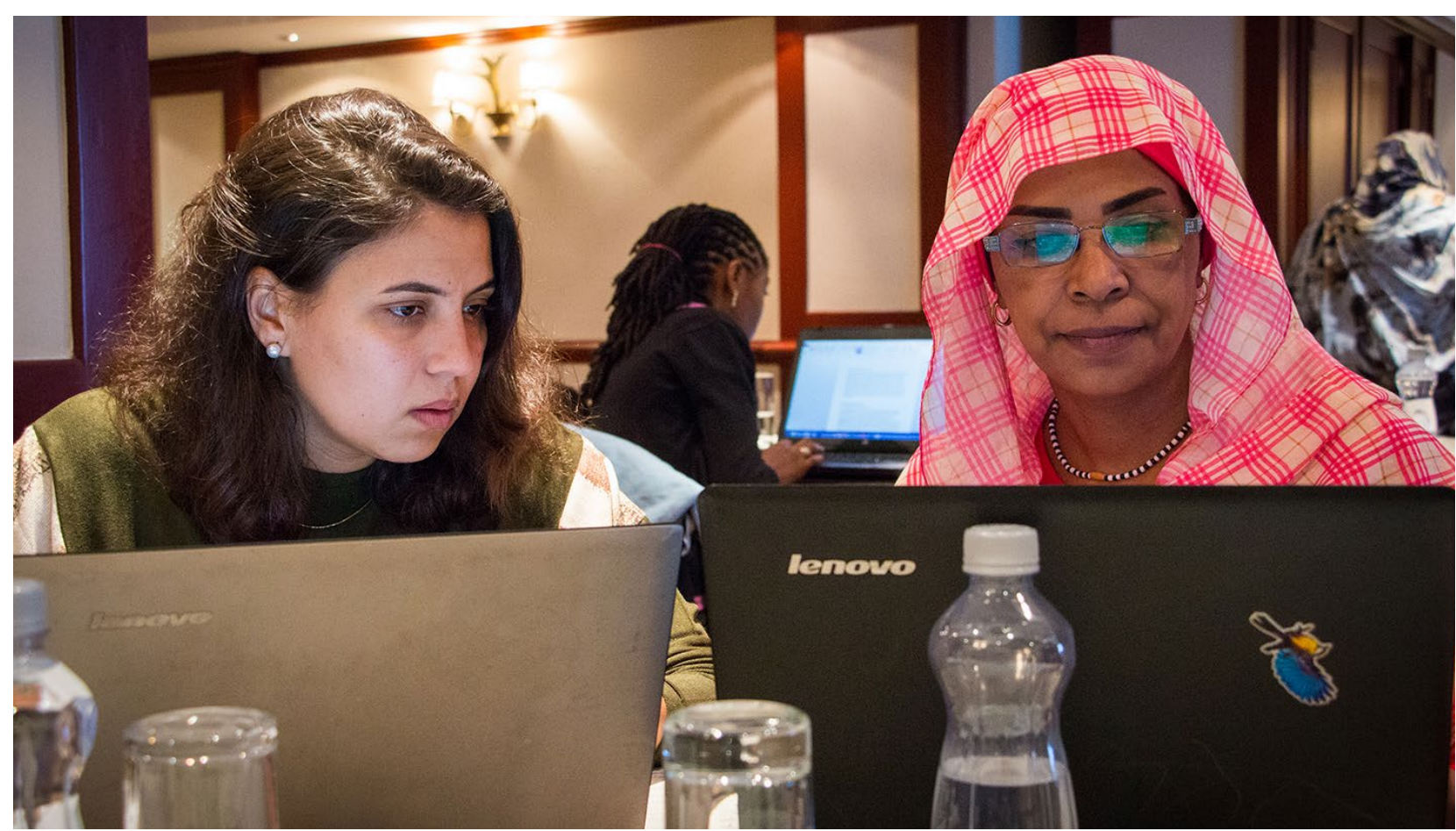

In the past, researchers from Northern institutions designed and led most studies on FGM/C. To build a sustainable legacy of locally led research, the consortium supported African researchers from the beginning, linking research organisations in both the North and the South to carry out the research programme.

The consortium strengthened the capacity of more than 35 early- and mid-career research professionals by having them work side-by-side with experts in the field and attend training workshops. As the earlycareer researchers took on increasingly senior roles, they began to support less-experienced research teams in other study sites. Many of the researchers gained critical skills in innovative quantitative and qualitative methods, and ultimately published their study results in international, peer-reviewed research journals.
Training sessions took place before, during, and after the research to clarify evidence gaps and prioritise research questions, to ensure that sound and reliable evidence would be produced to the highest scientific and ethical standards, and to reinforce researchers' capacity to communicate evidence effectively to decisionmakers.

"The consortium has heavily emphasised capacity building for young women and Africa-based researchers... It has enabled me to take more of a lead role in terms of study design, study implementation, as well as research uptake."

OTIBHO OBIANWU, PROGRAMME MANAGER, POPULATION COUNCIL, NIGERIA

As a result of the programme's capacity-strengthening efforts, two of the consortium's researchers received global recognition for their work: Salma Abou Hussein (Population Council, Egypt) was recognised as a "Hidden Hero" in the movement to end FGM/C by The Girl Generation, and Otibho Obianwu (Population Council, Nigeria) was selected as a 2019 Paula Kantor Award recipient by the International Center for Research on Women. 


\section{Enhanced Advocacy for Research Uptake}

Programme staff involved a range of decision-makers throughout the research process to ensure that the evidence generated would inform policies, programme development, and strategic investments. Because FGM/C has social, cultural, legal, political, and health dimensions, a wide range of audiences-from the highest-level policymakers to community leaders and families-needed to be informed, empowered, and mobilised to bring about change. The consortium's role was to ensure the best evidence would inform the process of change. Stakeholders had the opportunity to have input on research questions, and conversely, the researchers gained a "seat at the table" in discussions regarding FGM/C policies and programming.

\section{"When it comes to research uptake, it was very important that we start thinking about our stakeholders in the beginning, the people that are going to use the findings coming from our study."}

\section{DENNIS MATANDA, PROGRAMME OFFICER,} POPULATION COUNCIL, KENYA

One of the programme's most important legacies was increasing the demand for evidence from health professionals, associations, regulatory bodies, and programme implementers. Consortium staff brought together the key players working on FGM/C in their respective countries and set the stage for change. As a result, the consortium's work has become part of the $\mathrm{FGM} / \mathrm{C}$ response in much of Africa.

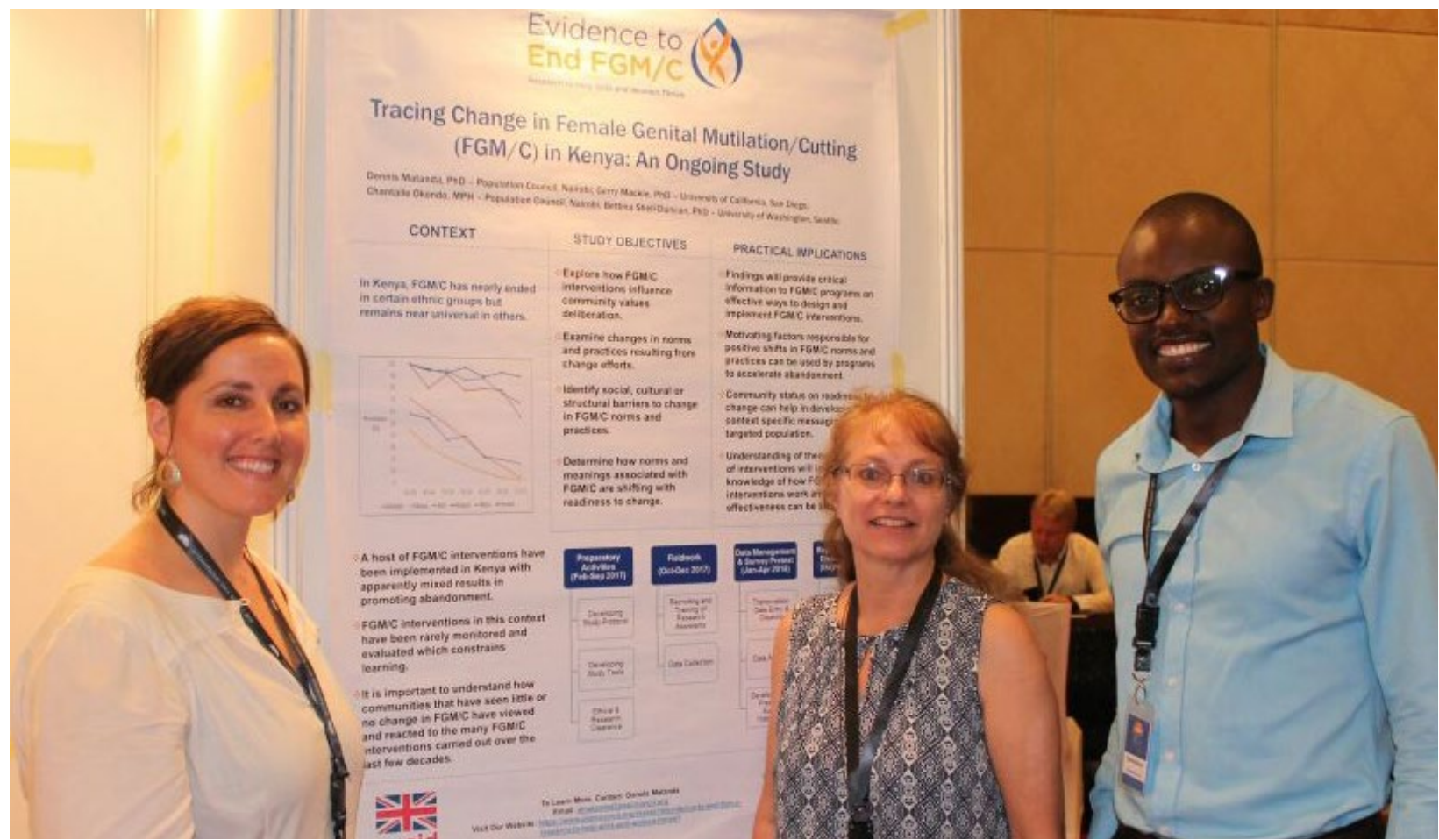

To communicate research effectively, team members identified who needed information and distilled the results in easy-to-understand language and formats. The consortium shared research through numerous channels: conference presentations, workshops, peer-reviewed journal articles, webinars, print and broadcast media, consortium members' websites, videos, briefs, blogs, and social media.

In Egypt, for example, the programme disseminated study findings on health care providers' and mothers' perceptions about medicalised cutting to government representatives, nongovernmental organisations, donors, researchers, and medical practitioners. The study fuelled much-needed discussion on why doctors are not held accountable for breaking the law and on how to address loopholes in the law's implementation. The study's dissemination provided a platform to highlight the importance of including FGM/C within the medical schools' curriculum.

WATCH RESEARCH UPTAKE VIDEO 
"So in a way using different mediums, whether it was video, social media, producing briefs, and also having posters that simplified the evidence, I think, had a huge impact...."

CHANTALLE OKONDO, PROGRAMME OFFICER, POPULATION COUNCIL, KENYA
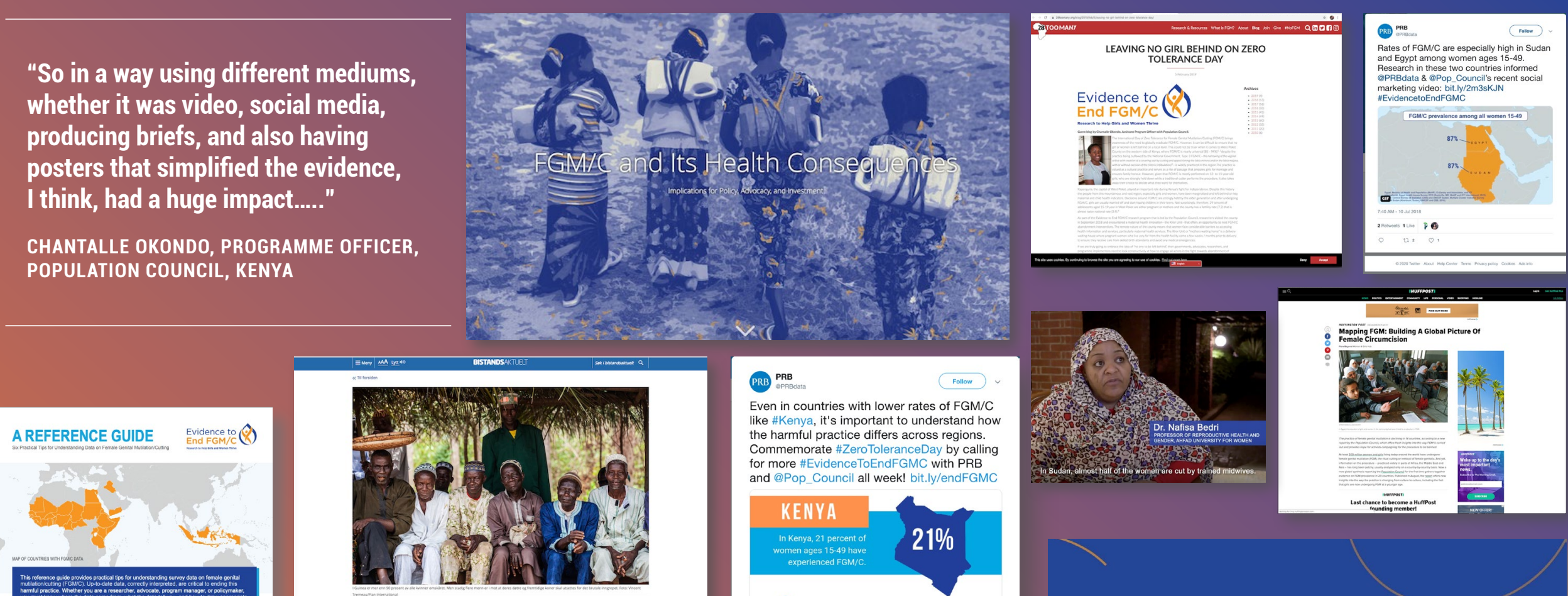

Menn sier nei til kvinnelig omskjæring

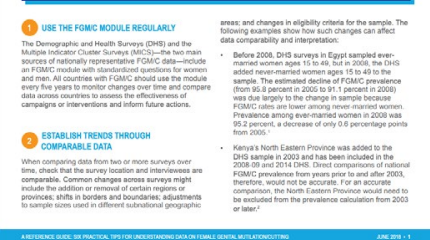

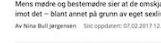

.

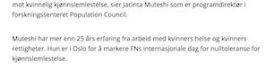

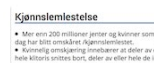

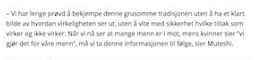
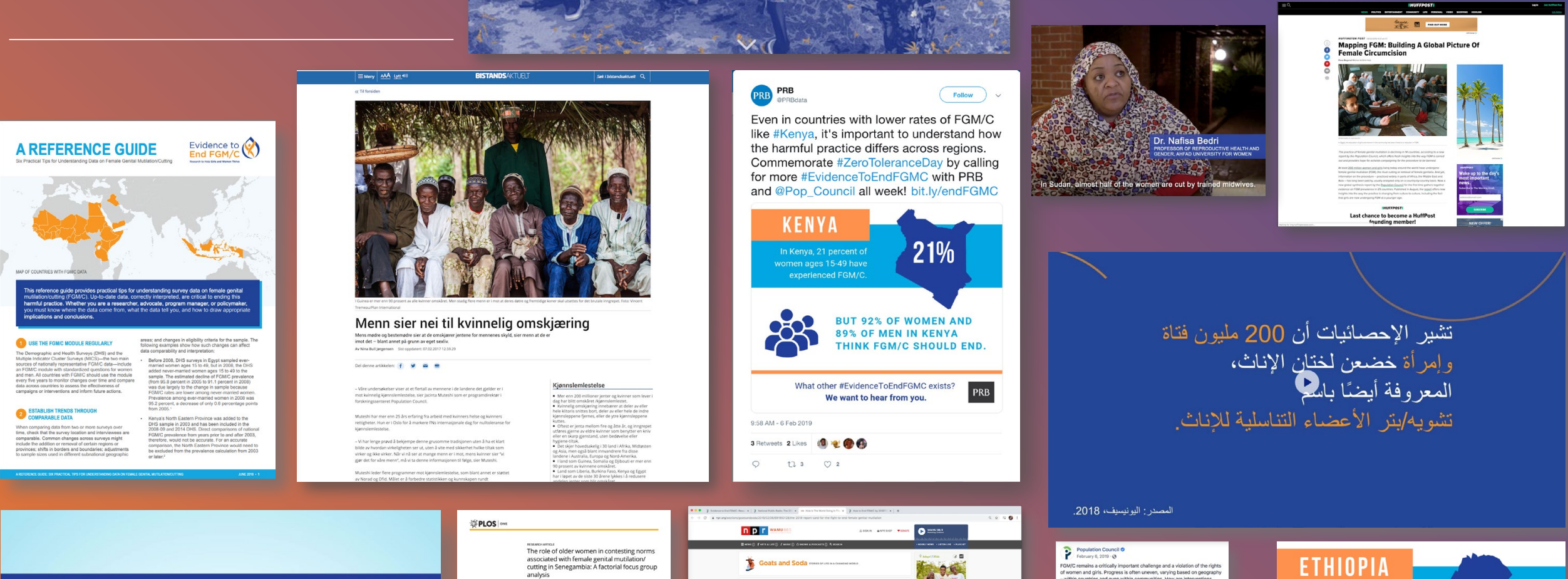

Four primarily qualitative studies explored:

Why families choose health care providers to perform FGM/C

Why health care providers choose to offer FGM/C
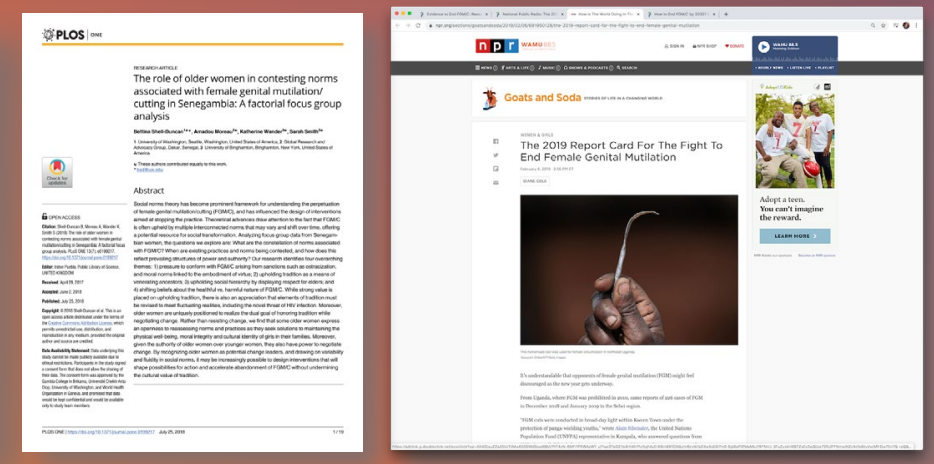

المسر: اليرئيس، 2018.

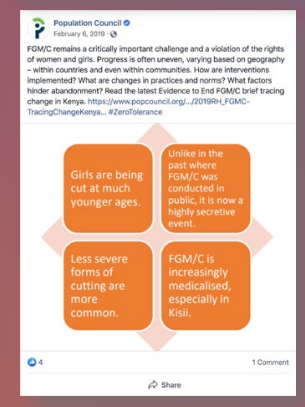

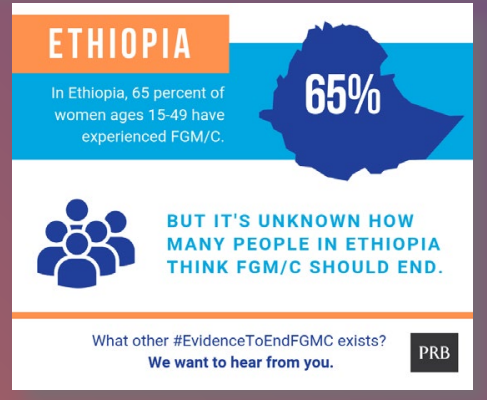




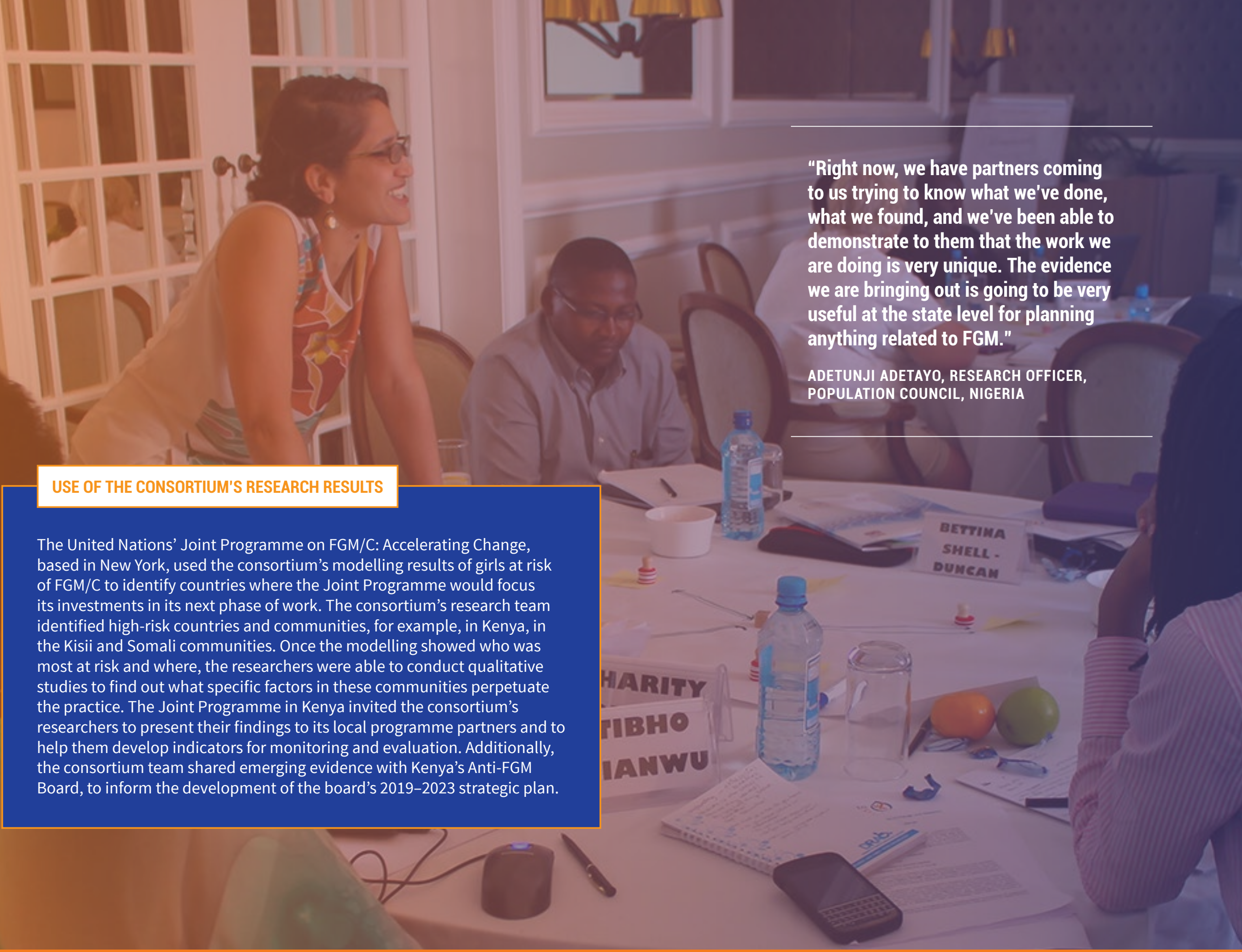




\section{Recommendations}

The consortium's research sheds light on key areas for future investments that would ensure that FGM/C policies and programmes are informed by rigorous evidence. The recommendations below stem from the lessons learnt on how local variations, social and cultural underpinnings, the health sector, and laws influence the practice of FGM/C.

\section{POLICY AND PROGRAMME ACTIONS}

\section{EMERGING EVIDENCE FROM THE CONSORTIUM UNDERSCORES THE NEED FOR POLICYMAKERS AND DEVELOPMENT PARTNERS TO:}

Make targeted investments based on evidence about patterns of $\mathrm{FGM} / \mathrm{C}$ and the specific locations where it is practised.

Strengthen the capacity of health care and law enforcement professionals to address FGM/C effectively.

Strengthen linkages among the legal, educational, and health sectors and develop multisectoral responses at decentralised levels of authority that build on existing institutions and functions.

Support local research capacity to ensure that FGM/C responses are informed by reliable evidence and tailored to the local context.

Focus abandonment efforts on family and community members who decide whether girls are cut, including fathers, health workers, traditional cutters, traditional birth attendants, and religious and community leaders.

\section{FUTURE DIRECTIONS IN RESEARCH}

TO ADDRESS REMAINING GAPS IN KNOWLEDGE, RESEARCHERS SHOULD:

Use innovative methods such as spatio-temporal modelling (which compares data across time and space) to generate evidence at the subnational level to ensure that resources are invested in areas with the greatest needs.

Conduct longitudinal (long-term) research to examine barriers to change, behavioural changes, and the sustained impact of interventions over time.

Assess whether social and cultural shifts are associated with communities' readiness to abandon the practice and what approaches work to address these shifts.

Conduct implementation research to identify practical and cost-effective interventions within the health and legal sectors to strengthen systemwide efforts to promote $\mathrm{FGM} / \mathrm{C}$ abandonment. 
The tools that have been developed over the course of this work and the insights gained from the research on the ground will inform precisely the kinds of programmes that are likely to be effective and to provide an infrastructure for research that is rigorous."

KATHRYN YOUNT, ROLLINS SCHOOL OF PUBLIC HEALTH, EMORY UNIVERSITY, USA MEMBER, INDEPENDENT CONSORTIUM ADVISORY GROUP

Innovative research methods, new evidence, and strong partnerships drove the consortium's success. Wide-ranging partnerships brought together researchers, civil society members, government officials, and technical experts to find new answers to a seemingly intractable problem. Going forward, such partnerships among institutions with well-established national, regional, and global networks will be key to ensuring that evidence is effectively used to influence policy and programme actions. 


\section{References}

Unless otherwise indicated, resources are published by Evidence to End FGM/C: Research to Help Girls and Women Thrive, Population Council, New York. For a complete list of resources on these and other topics, see the Evidence to End FGM/C website.

\section{PROGRAMME OVERVIEW}

Evidence to End FGM/C: Research to Help Girls and Women Thrive (fact sheet).

Muteshi-Strachan, Jacinta. 2016. The FGM/C research programme (presentation).

\section{UNDERSTANDING LOCAL VARIATIONS}

Kandala, Ngianga-Bakwin et al. 2019. A spatial analysis of the prevalence of female genital mutilation/cutting among 0-14-year-old girls in Kenya. International Journal of Environmental Research and Public Health 16 (21).

Kandala, Ngianga-Bakwin et al. 2017. Modelling and mapping of girls' female genital mutilation/cutting. (FGM/C) in the context of economic, social, and regional disparities: Kenya Demographic and Health Surveys 1998-2014.

Kandala, Ngianga-Bakwin et al. 2020. Modelling and mapping of state disparities associated with female genital mutilation/cutting prevalence among girls aged 0-14 years in Nigeria: Evidence from DHS and MICS 2003-2017 (forthcoming).

Kandala, Ngianga-Bakwin and Bettina Shell-Duncan. 2019. Trends in female genital mutilation/cutting in Senegal: What can we learn from successive household surveys in sub-Saharan African countries? International Journal for Equity in Health 18 (25).

Matanda, Dennis et al. 2020. Female genital mutilation/cutting in Senegal: Is the practice declining? Descriptive analysis of Demographic and Health Surveys 2005-2017 (forthcoming).

Population Reference Bureau. 2020. Understanding local variation in how female genital mutilation/ cutting declines, changes, or persists: Analysis of household survey data for Kenya, Nigeria, and Senegal (forthcoming).

\section{CHANGES IN SOCIAL AND CULTURAL UNDERPINNINGS}

Galal, Salma et al. 2020. Female genital mutilation/ cutting decision-making process and the role of gender power relations in Egypt (forthcoming).

Getaneh, Mehari et al. 2020. Exploring changes in female genital mutilation/cutting: Shifting norms and practices among communities in Fafan and West Arsi Zones, Ethiopia (forthcoming).

Kandala, Ngianga-Bakwin et al. 2018. Secular trends in the prevalence of female genital mutilation/cutting among girls: A systematic analysis, BMJ Global Health 3: e000549
Matanda, Dennis et al. 2018. Tracing change in female genital mutilation/cutting: Shifting norms and practices among communities in Narok and Kisii counties, Kenya.

Moreau, Amadou and Bettina Shell-Duncan. 2020. Tracing change in female genital mutilation/cutting through social networks: An intersectional analysis of the influence of gender, generation, status and structural inequality (forthcoming).

Powell, Richard A. et al. 2020. Exploring the nature and extent of normative change in $\mathrm{FGM} / \mathrm{C}$ in Somaliland (forthcoming).

Powell, Richard A. and Mohamed Yussuf. 2018. Changes in FGM/C in Somaliland: Medical narrative driving shift in types of cutting.

Sabahelzain, Majdi et al. 2019. Decision-making in the practice of female genital mutilation or cutting in Sudan: A cross-sectional study, Global Health Research and Policy 4 (5).

Shell-Duncan, Bettina et al. 2018. The role of older women in contesting norms associated with female genital mutilation/cutting in Senegambia: A factorial focus group analysis, PLOS ONE 13 (7): e0199217.

Wahba, Nada et al. 2020. Improved understanding of female genital mutilation/cutting abandonment in Egypt (forthcoming) 


\section{ROLE OF HEALTH SYSTEM}

Bedri, Nafisa et al. 2018. Medicalisation of female genital mutilation/cutting in Sudan: Shifts in types and providers.

Dirisu, Osayuyi et al. 2020. A diagnostic assessment of health systems response to FGM/C management and prevention in Nigeria (forthcoming).

Greenbaum, Charlotte. 2018. Understanding the Impact of Medicalization on Female Genital Mutilation/ Cutting (web feature).

Kabiru, Caroline. 2018. Engaging Health Care Professionals as Allies to End FGM/C (blog).

Kimani, Samuel et al. 2016. Health impacts of female genital mutilation/cutting: A synthesis of the evidence.

Kimani, Samuel and Chantalle Okondo. 2020. A diagnostic assessment of health systems response to female genital mutilation/cutting management and prevention in Kenya (forthcoming).

Kimani, Samuel and Caroline W. Kabiru. 2018. Shifts in female genital mutilation/cutting in Kenya: Perspectives of families and health care providers.

Kimani, Samuel and Bettina Shell-Duncan. 2018. Medicalized female genital mutilation/cutting:

Contentious practices and persistent debates, Current Sexual Health Reports 10 (1): 25-34.
Obianwu, Otibho et al. 2018. Understanding medicalization of female genital mutilation/cutting: A qualitative study of parents and health workers in Nigeria.

Rodehau, Carolyn. 2018. FGM/C and Health

Consequences: Implications for Policy, Advocacy, and Investment (web feature).

Shell-Duncan, Bettina et al. 2018. Trends in medicalisation of female genital mutilation/cutting: What do the data reveal?

\section{ROLE OF LEGAL SYSTEM}

Meroka-Mutua, Agnes et al. 2020. Assessing when and how law is effective in reducing the practice of FGM/C in Kenya (forthcoming).

Wouango, Joséphine et al. 2020. When and how does law effectively reduce the practice of FGM/C: A crossborder study in Burkina Faso and Mali (forthcoming).

\section{IMPROVEMENTS IN METHODS}

Esho, Tammary et al. 2019. Measurement of the sexual health and wellbeing of women who have undergone female genital mutilation/cutting: A scoping review, International Journal of Sexual Health 31 (1): 92-108.

Shell-Duncan, Bettina et al. 2019. Reference guide for data collection: Qualitative social network interviews.
Shell-Duncan, Bettina et al. 2019. Reference guide: Factorial focus group analysis methods for studying social norm change.

Shell-Duncan, Bettina. 2017. Consideration on the use and interpretation of survey data on FGM/C, in: Els Leye \& Gily Coene (eds.), Researching Female Genital Mutilation/Cutting (e-book), Proceedings from the Second International Academic Seminar: Female Genital Mutilation/Cutting, Brussels.

\section{CAPACITY AND RESEARCH UPTAKE}

Greenbaum, Charlotte and Reshma Naik. 2018. A Reference Guide: Six Practical Tips for Understanding Data on Female Genital Mutilation/ Cutting.

Kolb, Melina and Reshma Naik, 2017. Communicating Research Through Data Visualization. 


\section{Acknowledgments and Credits}

\section{ACKNOWLEDGMENTS}

Lori S. Ashford of Clarity Global Health prepared this legacy document in collaboration with Reshma Naik and Charlotte Greenbaum of the Population Reference Bureau (PRB) and with technical input from Jacinta Muteshi-Strachan, Esther Lwanga, and Caroline Kabiru of the Population Council, Kenya. Thanks are due to Population Council staff members and others who reviewed various drafts: Hazel Barrett, Michelle Hindin, Erika Martin, Dennis Matanda, and Chantalle Okondo. Heidi Worley of PRB edited the material and Jessica Woodin and Anneka Van Scoyoc of PRB created the graphic design.

The Evidence to End FGM/C: Research to Help Girls and Women Thrive generates evidence to inform and influence investments, policies, and programmes for ending female genital mutilation/ cutting in different contexts. Evidence to End FGM/C is led by the Population Council, Kenya in partnership with the Africa Coordinating Centre for the Abandonment of Female Genital Mutilation/Cutting (ACCAF), Kenya; the Global Research and Advocacy Group (GRAG), Senegal; Population Council, Nigeria; Population Council, Egypt; Population Council, Ethiopia;
MannionDaniels, Ltd. (Md.); Population Reference Bureau (PRB); University of California, San Diego (Dr. Gerry Mackie); and University of Washington, Seattle (Prof. Bettina Shell-Duncan).

This document is an output from a programme funded by UK Aid from the UK government for the benefit of developing countries. However, the views expressed and information contained in it are not necessarily those of, or endorsed by the UK government, which can accept no responsibility for such views or information or for any reliance placed on them.

\section{$\times 12$ 㭗 UKaid}

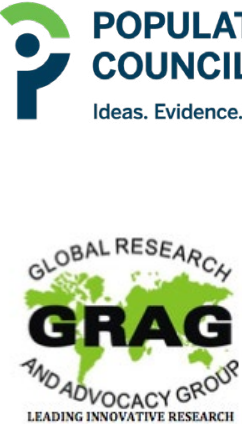

\section{PRB}
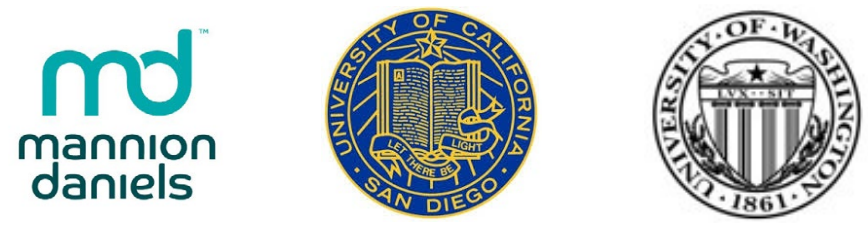

PHOTO CREDITS

Page 21: Hans-Martens

All other photos taken by the consortium 